Yannou B., Farel R., Cluzel F., Bekhradi A., Zimmer B. (20IB) 'The UNPC innuvativeness set of indicators for idea or project selection and maturation in healthcare', 5, №. 3-4, pp. 205-221, Internationa/ Jaurna/ of Design Creativity and Innavatian, dai: 10.1080/21650349.2016.1161562

\title{
The UNPC innovativeness set of indicators for idea or project selection and maturation in healthcare
}

\author{
Bernard Yannou, corresponding author \\ Université Paris-Saclay, CentraleSupélec, Laboratoire Genie Industriel, \\ Grande voie des vignes, 92290, Chatenay-Malabry, France \\ +33141 1315 21, bernard.yannou@ @entralesupelec.fr
}

\section{Romain Farel \\ Paris Saclay Efficacité Énergétique (PS2E), 1, chemin de la porte des loges, BP 126, 78354 Jouy-en-Josas Cedex, France \\ +331390722 65, romain.farel@institut-ps2e.com \\ François Cluzel \\ Université Paris-Saclay, CentraleSupélec, Laboratoire Genie Industriel, Grande voie des vignes, 92290, Chatenay-Malabry, France \\ +33141131328, francois.cluzel@ centralesupelec.fr}

\author{
Alborz Bekhradi \\ Université Paris-Saclay, CentraleSupélec, Laboratoire Genie Industriel, \\ Grande voie des vignes, 92290, Chatenay-Malabry, France \\ alborz.bekhradi@centralesupelec.fr

\section{Benjamin Zimmer} \\ Silver Valley, 11 rue Pierre Rigaud, 94200 Ivry Sur Seine, France \\ +33954 2308 85, benjamin.zimmer@ silvervalley.fr
}

\begin{abstract}
A great deal of work has been done to characterize entire sets of ideation indicators as well as isolated factors of innovativeness. Nevertheless, entire sets of innovativeness indicators are essential in business innovation competitions, as well as within companies in order to select promising innovation seeds. In this paper, a complete set of innovativeness indicators in the context of innovating in healthcare is proposed. The UNPC innovativeness model, standing for usefulness, newness, profitability and (proof of) concept, has been tested and validated over a period of 4 years within the largest European innovation cluster in the silver economy. Four authentic examples of innovation selections are analysed. They illustrate how the UNPC model is able to provide clear and efficient guidance for better decision-making in the context of innovating for the elderly. In addition, a framework for monitoring an innovative idea or project, and for increasing its maturity, is proposed. The UNPC monitoring process starts with the SWOT analysis of competing ideas. It then becomes dynamic, looking for new evidence for increasing the certainty and impact of UNPC proofs of the competing ideas. The model has been successfully used for upgrading a popular smart application on activity tracking.
\end{abstract}

Keywords: innovativeness indicators, ideation indicators, idea maturity, maturity monitoring, innovation process, idea selection, innovation competition 


\section{Ideation versus innovativeness metrics}

Various proposals have recently been made for measuring qualities of ideation tasks (Maher and Fisher, 2012). Several models exist to measure the efficiency of this ideation process. Shah, Smith and VargasHernandez (2003) proposed four separate effectiveness measures: novelty, variety, quality and quantity. Novelty measures how unusual or unexpected an idea is, compared to other ideas. Variety is a size measurement of the explored solution space. Quality is a measurement of the feasibility of an idea and how close it comes to meeting design specifications. Quantity is the total number of ideas generated. Sarkar and Chakrabarti (2011) addressed methods for assessing innovation in such a way as to integrate the notion of development deadlines and degree of creativity, two factors they found missing in Shah's metrics. They also highlighted the need to define the degree of creativity of products where creativity is considered a function of novelty and usefulness. The SAPPhIRE model, developed by Chakrabarti, Sarkar, Leelavathamma, and Nataraju (2005) proposed a framework for design to encourage novelty. Using the linkography principle (Goldschmidt, 1990), Goldschmidt and Tatsa (2005) determined if a given "good" idea is related to other ideas reported in classroom discussions of students' projects in progress. Kan and Gero (2008) showed how to compute novelty with linkographs. Recently, Grace, Maher, Fisher, and Brady (2014) proposed a method of computing the surprise effect of a product. They used a distance metric to compare the attributes of a creative product and the attributes of similar products in the market.

Much work has also been undertaken to characterize components of innovativeness metrics, but rare are the works that propose complete sets of innovativeness metrics in given contexts. Innovativeness metrics concern more the economic success of an entrepreneurial or intrapreneurial venture; thus, their focus is on the results rather than the creative means. As defined by the authors in (Yannou, Zimmer, Farel, Jankovic, and Stal Le Cardinal, 2013), innovativeness metrics aim at assessing the likelihood, at any stage of maturity, of an idea or a project becoming a successful innovation. Such innovativeness metrics are essential in business innovation competitions organized by private/public initiatives, as well as within companies for selecting promising innovation seeds.

Literature in marketing has tended to explore innovation or innovativeness rather than creativity. Here, an innovation is a combination of a certain degree of value-add and a certain degree of newness (Wright, 2012). A value-add is a usefulness indicator from the perspective of the end-user at the time the product is launched onto the market. This usefulness is hard to assess for designers, especially when end-users and other value stakeholders do not share the same expectations. This usefulness is also hard to automate except when modeling the preferences of end-users or customers, in the context of competing offers and with the consciousness of jobs-to-be-done (Christensen, 2003, 2011). Measuring the perceived valueadd of usefulness of ideas/products is also of utmost importance for guaranteeing market success. Indeed, this is the principle of the popular blue ocean strategy developed by Kim and Mauborgne (2005). Recently, the authors proposed a method to compute usefulness indicators of design concepts (Bekhradi, Yannou, Farel, Jena, and Zimmer, 2014; Bekhradi, Yannou, Farel, Zimmer, and Chandra, 2015) by usage segmentation techniques, measuring the degree of dominance of a product or an idea by summation over all usage segments. A first approach considers the effectiveness of the product/idea weighted by the size of the usage segment. This is the notion of usage coverage indicators (Yannou, Yvars, Hoyle, and Chen, 2013). The second approach compares the usefulness dominance of the product/idea under study to existing offers (Bekhradi et al., 2015).

Other authors claim that "quantity breeds quality" is a poor principle as a component of innovativeness for several reasons. Kazakci, Gillier, Piat, and Hatchuel (2014), experimenting on practical ideation situations, observed that (in abstract, page 199) "[r]esults lead to the rejection of the classical 'quantity breeds quality' hypothesis. Rather, we observe that successful groups are the ones who produce a few original propositions that hold great value for users while looking for ways to make those propositions 
Yannou B., Farel R., Cluzel F., Bekhradi A., Zimmer B. (20IG) 'The UNPC innovativeness set of indicators for idea aг ргоject selection and maturation in healthcare', 5, №. 3-4, pp. 205-2Z1, Internationa/ Lourna/ of Design Lreativity and Innavation, dai: 10.1080/21650349.2016.||6|562

feasible." For a designer, feasibility, which can also be called proof-of-concept, may be a constraint leading to better idea selections and inspiration. In summary, it is important to assess idea feasibility in design practice so as to increase the probability of leading to successful innovation on the market (Kazakci et al., 2014).

In addition, the authors showed that we cannot separate the question of ideation measurements from the pertinence of exploration-exploitation of the adopted innovation process. The Radical Innovation Design (RID) methodology developed by the authors (Yannou, 2015; Yannou, Jankovic, Leroy, and Okudan Kremer, 2013) aims to generate a low number of conceptual ideas or solutions. This is because RID is a process of systematic investigation at the front end of innovation along with a continuous uncertainty reduction process that converges toward a small set of value buckets. It is not therefore a stochastic generation of interesting ideas in the "thinking outside the box" paradigm. Value buckets are "combinations of important problems/pains occurring during characteristic usage situations, and for which existing solutions are generally neither useful nor efficient" (Yannou, 2015). The principle here is "let us investigate the problem setting, focusing on a small number of value buckets that are the starting points of focused innovations". The better value buckets are identified, the more likely it is that creative ideas will become successful innovations on the market, because of the immediate perceived usefulness and newness.

Newness has been studied by Talke, Salomo, Wieringa, and Lutz (2009) as a component of innovativeness metrics. We agree with the authors that "design newness is never discussed among the dimensions of product innovativeness".. This is due to the inherent difficulty of correlating a measure of market success with a level of newness. The authors clearly establish that two aspects of newness must be considered: design (apparent) newness and technical newness. Both of these factors "are important drivers of car sales. But, while design newness has a positive impact right after the introduction and persists in strength over time, technical newness drives sales with a lagged effect and decreases toward the end of the life cycle." Hence, these authors validate newness as a component of innovativeness.

Some authors, such as Kornish and Ulrich (2014), have been interested in predicting the success and profitability of a new product or service launch. They advocate commonsense: conventional surveys of consumers are a better way of determining what a "good" idea is, rather than ratings by even highly experienced experts. We agree with their conclusion in their case study of innovating in household consumer products. However, in cases like the one we characterize as contexts of pain-driven and needseeker useful innovations (Yannou, 2015) such as "design for healthcare", we strongly disagree. For instance, in the case of designing for the elderly, the traditional market does not exist as the users (the elderly) are often not the purchaser, and the purchasers are often not the prescribers (medical doctors). In these cases, who should be interviewed? In addition, the success of an innovation depends on a variety of factors and stakeholders: for example, in this case, ratings by highly experienced experts provide better clues than interviewing the elderly! Four examples are provided in section 3 below to support this claim.

Lastly, we are conscious that many authors study the "wow effect" and other emotional experiences as components of people's attraction to novel products or services (Boatwright and Cagan, 2010). As we are restricting our set of innovativeness indicators to the healthcare sector, we believe that:

- usefulness is far preferred to the wow effect,

- and the wow effect is not a major factor in this sector as social security and health insurance drive the funding support of a medical solution.

We have therefore seen that there are different notions of usefulness, feasibility, newness (design/apparent and technical) or novelty, profitability, wow effect and emotional impact. But there have been few attempts to propose a whole set of innovativeness metrics. This is due to the diversity of 
innovation situations and realities that condition innovation success in the context of an entrepreneurial or intrapreneurial venture.

In this paper, we propose a whole set of innovativeness metrics in the context of pain-driven and needseeker useful innovations (Yannou, 2015) such as "design for healthcare" and in situations of business innovation competitions organized by private/public initiatives as well as within companies for selecting promising innovation seeds.

In section 2, we define our UNPC model of innovativeness indicators in the light of the literature and some of our previous work. In section 3, we illustrate for the first time the qualitative use of a UNPC innovativeness set of indicators for innovative project selection in the field of "designing for the elderly". In this case, the jury members of an innovation competition changed their decision concerning a given project after considering the whole set of UNPC proofs. In section 4, our UNPC model is used to monitor innovative ideas, progressively consolidating each of the usefulness - newness - profitability - concept proofs and reinforcing the likelihood of market success. In section 5, UNPC monitoring is applied to a real industrial project which consists of upgrading an e-healthcare activity tracking application to personal health coaching facilities. Section 6 is dedicated to results and discussion. UNPC monitoring has been successful since a popular smart application has been upgraded. The tool interface is presented and further research evoked.

\section{Introducing the UNPC model as innovativeness metrics in need seeker useful innovation contexts}

Boston Consulting Group propose categorizing innovation strategies into Technology drivers, Market readers and Need seekers. Radical Innovation Design (RID) methodology (Yannou, 2015; Yannou, Jankovic, et al., 2013) creates essential values (Yannou, 2015), adopting a need seeker innovation strategy. This is indeed a pain-driven process where problems are identified and prioritized in different usage situations of a targeted set of people. Ideation really starts after the determination of value buckets which guarantee coming up with blue ocean type innovations, as advised in (Kim and Mauborgne, 2005), i.e. useful problem chunks not yet satisfactorily solved. The authors have shown that a usefulness indicator may be computed from segmentation of usage situations by summation of the degree of dominance of a product or an idea on all usage segments (Bekhradi et al., 2015). This is why we define usefulness (see Table 1) as the ability to cover usage and needs situations of users / stakeholders for which important needs are covered, suffering is alleviated, and/or malfunctions of existing systems are improved. In case of high usefulness, the assumption is that the innovative idea is likely to become successful unless the market remains insensitive or does not perceive the lowering of pains in typical usage situations. Here, one can speak of a non-educated market.

As our context is that of situations of business innovation competitions organized by private/public initiatives as well as within companies for selecting promising innovation seeds, a newness indicator is needed. We propose the proofs of newness (see Table 1) to be threefold:

- It can be a real technical newness, possibly patentable, as discussed in (Talke et al., 2009).

- It can also be a usage newness. Here we differ from Talke et al (Talke et al., 2009) who prefer to consider design or apparent newness instead. In a service-oriented spirit and in a "design for healthcare" context, we believe that clients and end-users do not always care about technical newness or design newness, provided that the service outperforms on the job to be done, or that usage or user experience is transformed or improved.

- It may be the case that a real usage or technical newness may be poorly perceived as the market may be neither informed nor sensitive, i.e. uneducated. This is why, whatever the usage or technical newness, the degree of perceived newness by clients or end-users, i.e. how much newness is appreciated and valued, must also be considered. 
Yannou B., Farel R., Cluzel F., Bekhradi A., Zimmer B. (20IG) 'The UNPC innavativeness set of indicatars far idea or praject selection and maturation in healthcare', 5, №. 3-4, pp. 205-2Z1, Internationa/ Lourna/ of Design Lreativity and Innavation, dai: 10.1080/21650349.2016.||6|562

We propose a profitability indicator (see Table 1) that embeds expected profitability for the company as well as for customers. Profitability is related to costs: from the viewpoint of producers, this is the elementary margin on a product unit; from the viewpoint of user, this is the total cost of ownership.

In our case of innovating in healthcare contexts, the success in terms of market size tends to be more embedded in Usefulness (see Table 1 for our definition). To complete this indicator of profitability, we include strategic aspects of the company that go beyond the single innovation. This could include the ability to improve brand image, to increase the average revenue per user, to conquer new markets or to make clients more loyal to the brand or company. This criterion of profitability is never used in ideation metrics, as it is probably too oriented towards marketing. In practice it quickly becomes crucial. Having worked on many innovation projects with companies, the authors are convinced that any innovation must prove to be profitable for both the company and the end-users in terms of global lifecycle cost, if the innovation is to be successful.

Finally, as suggested by Kazakci et al. (2014), feasibility is crucial for innovation success in practice. We propose to call it proof of concept and to consider a twofold definition:

- On the side of users, these are proofs that the conceptual solution or prototype functions effectively and efficiently in expected situations.

- On the side of the manufacturer, these are proofs of technological and industrial feasibility.

Table 1. Definition of the Usefulness-Newness-Profitability-Concept proofs

\begin{tabular}{|c|c|}
\hline Proof type & Definition \\
\hline $\begin{array}{l}\text { Proof of Usefulness } \\
\text { (U) }\end{array}$ & $\begin{array}{l}\text { Proofs of Usefulness exist when important needs in frequent usage situations } \\
\text { may be satisfied or covered, people's suffering or pains alleviated or } \\
\text { malfunctions of existing systems improved. In case of high usefulness, the } \\
\text { market size is likely to be large and, consequently, market esteem for the } \\
\text { product high. }\end{array}$ \\
\hline $\begin{array}{l}\text { Proof of } \\
\text { Newness (N) }\end{array}$ & $\begin{array}{l}\text { Proofs of Newness are composed of three aspects: } \\
\text { - Perceived newness by clients or end-users, appreciated and valued } \\
\text { by them. } \\
\text { - } \quad \text { Real technical newness, possibly patentable. } \\
\text { - Usage newness. Note that real usage newness may be poorly } \\
\text { perceived as the market may be not educated or sensitive. }\end{array}$ \\
\hline $\begin{array}{l}\text { Proof of } \\
\text { Profitability (P) }\end{array}$ & $\begin{array}{l}\text { It concerns expected Profitability for the company as well as for customers. } \\
\text { Profitability is related to costs: } \\
\text { - From the viewpoint of producers, this is the elementary margin on a } \\
\text { product unit. } \\
\text { - From the viewpoint of users, this is the total cost of ownership. } \\
\text { Proofs of Profitability may also characterize the ability to improve brand } \\
\text { image, to increase the average revenue per user, to conquer new markets or } \\
\text { to make clients more loyal (higher re-purchasing rate). }\end{array}$ \\
\hline $\begin{array}{l}\text { Proof of } \\
\text { Concept }(C)\end{array}$ & $\begin{array}{l}\text { Proofs of Concept are twofold: } \\
\text { - } \text { On the side of users, these are proofs that the conceptual solution or } \\
\text { prototype functions effectively and efficiently in expected situations. } \\
\text { - On the side of the manufacturer, these are proofs of technological } \\
\text { and industrial feasibility. }\end{array}$ \\
\hline
\end{tabular}

These four innovativeness indicators have already been proposed (Yannou, Farel, and Cluzel, 2015; Yannou, Zimmer, et al., 2013), but their definitions have been improved in Table 1 . The authors have already shown that this set of innovativeness indicators is highly relevant and complete both in situations of business innovation competitions organized by private/public initiatives as well as within companies for selecting promising innovation seeds. These four indicators are called proofs because they are designed to encourage assessment by expert designers or innovation jury members at different stages of the ideation and innovation process, after examination of evidence. The authors consider here that 
innovation is a probabilistic process which attempts to come up with the highest value creation for endusers. This is similar to the approach adopted by Thompson and Paredis (2010) for Rational Design Theory. In (Yannou et al., 2015; Yannou, Zimmer, et al., 2013), we have already proposed that this probabilistic view be modelled for any of $\mathrm{U}, \mathrm{N}, \mathrm{P}$ and $\mathrm{C}$ proof by two variables called impact (the proof value is more or less high) or certainty (this proof impact is more or less probable). In Table 2, impact may be valued between -3 and +3 depending on both the strength and the nature (positive or negative) aspects of U, N, $\mathrm{P}$ or $\mathrm{C}$ proof. For instance, an impact of $P_{-2}$ means that Profitability is notably bad, an impact of $N_{+1}$ means that Newness exists, but weakly. Certainty may be valued between 0 and $100 \%$ with increments of $25 \%$, depending on the certainty of the given proof of $\mathrm{U}, \mathrm{N}, \mathrm{P}$ or $\mathrm{C}$ type. For instance, a certainty of $75 \%$ referring to $P_{-2}$ means that it is highly probable that Profitability is bad.

Table 2. Rating scales of impact and certainty of UNPC proofs

\begin{tabular}{|c|c|}
\hline $\begin{array}{c}\text { Impact of a UNPC positive (+) or } \\
\text { negative (-) proof }\end{array}$ & Rating scale \\
\hline Null & 0 \\
\hline Weak & Icons \\
\hline Average & $+/-1$ \\
\hline Strong & $+/-3$
\end{tabular}

\begin{tabular}{|c|c|c|c|}
\hline Certainty of an UNPC proof & Probability & Rating scale & Icon \\
\hline Absent & $0 \%$ & 0 & \\
\hline Some elements & $25 \%$ & 1 & \\
\hline Serious elements - Presumptions & $50 \%$ & 2 & \\
\hline Highly probable - Credible & $75 \%$ & 3 & \\
\hline Undeniable and complete & $100 \%$ & 4 & \\
\hline
\end{tabular}

In (Yannou, Zimmer, et al., 2013), the UNPC model proved useful and relevant in monitoring innovativeness emergence in the context of an innovation cluster to select, grant and incubate the most promising innovative ideas or projects. It was clearly shown that the projects finally selected by jury members were also those that scored highest with a rating made of the summation of UNPC impacts and UNPC certainties, after formula (1).

$\sum_{p \in\{U, N, P, C\}}$ Impact $_{p}+\sum_{p \in\{U, N, P, C\}}$ Certainty $_{p}$

The UNPC model was successfully used a second time in the framework of delivering the final grade to innovation projects in a university engineering department. We found a remarkable correlation between the aggregate indicator given by formula (1) - taking an average across the jury members for each project - and the average grade assigned to the project by company representatives and which was assumed to "assess the potential of the given innovation to be successful in the market".

In the present paper, we propose a process to monitor and augment the probability of value creation or innovativeness, adopting the UNPC set of indicators. We may also speak of augmenting an idea or 
Yannou B., Farel R., Cluzel F., Bekhradi A., Zimmer B. (20IG) 'The UNPC innavativeness set of indicatars far idea or praject selection and maturation in healthcare', 5, №. 3-4, pp. 205-2Z1, Internationa/ Lourna/ of Design Lreativity and Innavation, dai: 10.1080/21650349.2016.||6|562

project maturity, maturity being widely used in companies to monitor development processes (e.g., TRLs maturity indicators).

\section{Practical use of UNPC model for rejecting or selecting ideas and projects for innovating in healthcare}

\subsection{Context of the largest European innovation cluster on silver economy}

The UNPC model has been used for 4 years in the largest European innovation cluster in the silver economy, i.e. the sector of product and service innovation for life quality of the elderly. In the Silver Valley innovation cluster (see http://www.silvervalley.fr/English-version), 200 private and public silver economy actors in the Paris region decided to elaborate favorable conditions to develop the senior market at national and international levels. Silver Valley has adopted the UNPC model to select ideas and projects deserving to be rewarded as well as incubated for two years.

Each year, about 8 ideas or projects out of 30 are awarded a prize in a business innovation competition called "Bourse Charles Foix". Among these 8, 3 are in addition incubated for two years so as to boost a startup company. An experienced jury (see http://www.silvervalley.fr/Bourse-Charles-Foix-2015) of 20 innovation experts, industrialists, investors, and experts of the elderly use UNPC assessments to make their decisions after a first dossier selection, an oral presentation made by the project holders, and an intensive debate. It is sometimes taboo in the innovation world to say that some ideas or innovative projects may be more or less useless, inapplicable, based on wrong causal/explanatory principles, fallacious, money-wasting or even dangerous. In the Silver Valley innovation jury, jury members understand that usefulness must be produced for the elderly, a product or service must effectively work in different usage situations (proof of concept), it must result in value creation for users and manufacturers (proof of profitability), and it must be novel to be selected (proof of newness). Jury members have not always shared the same opinions about which innovations for elderly people should be encouraged.

Below, four real life examples of "Bourse Charles Foix" 2012 and 2013 editions are commented on for the first time to illustrate how the UNPC model has provided clear and efficient guidance for better decision-making in the context of innovating for the elderly. For these four examples, during the jury deliberation, decisions to select a given project were made by brute project ordering. But the posterior examination of UNPC criteria finally inverted the decision at the very end of deliberation. These four examples demonstrate how UNPC is used qualitatively by jury members. The two first examples were not at first considered for selection, but they finally won the prize. The two last examples were initially ranked in top position, but were finally discredited after examination using a UNPC set of criteria.

\subsection{A rationale to bring out truly innovative projects}

The first innovative project was proposed by a young industrial designer. His observations in retirement homes showed that few activities were proposed to the elderly and, consequently, the elderly in these homes were often bored. In addition, activities they used to practice when they were fully active - such as gardening - were now forbidden for reasons of physical disability and retirement home safety rules and organization. An innovative gardening table project was imagined: a movable quadrant heightadjustable table with a set of ergonomic gardening tools (see Figure 1). The tools and the table were designed and tested along with the aid of elderly people and proved to be highly ergonomic (proof of concept), even for those who had hand disabilities or were wheelchair-bound. The solutions were patented and the newness was clearly perceived by health professionals as well as gardening stores. When the project was selected and incubated, there was a good likelihood that the profitability would be high; indeed, the elderly and professionals welcomed the product and the market appeared large. After four years, the startup company Verdurable (http://verdurable.fr/) has produced and sold 200 table sets and sells even more gardening tools sets. Sixty retirement homes and geriatric services in hospitals 
have been equipped with these gardening solutions, freeing up time for health personnel (proof of profitability) and providing happiness, pride and dignity to the elderly (proof of usefulness).

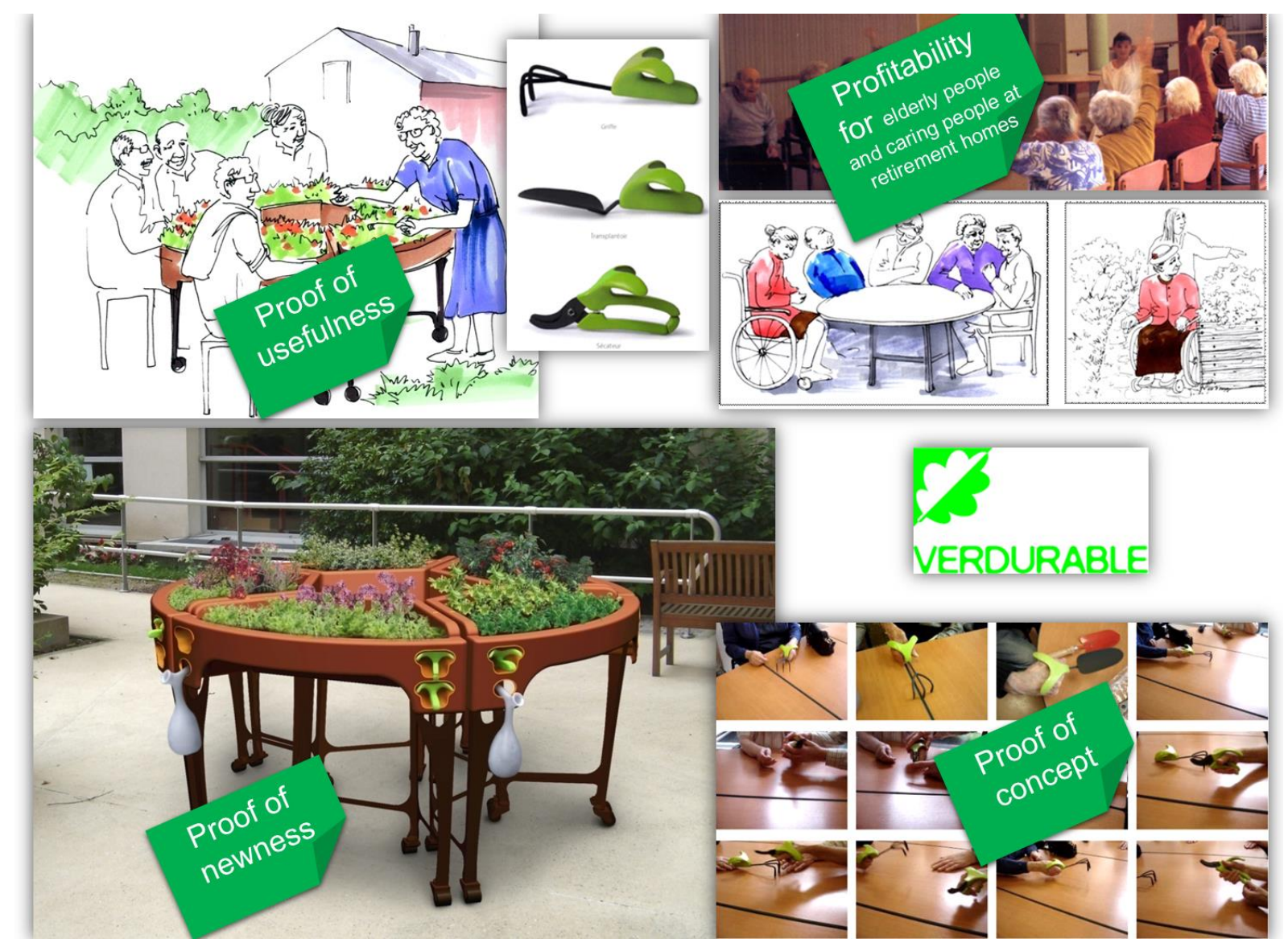

Figure 1. UNPC proofs for the gardening table project

The second example is an innovative hairdressing chair and furniture for elderly proposed by an experienced engineer. During a period of unemployment, he heard his wife complaining when she was hair dressing elderly people at geriatric hospitals, retirement homes or at home. For many elderly people, body motions are limited - for instance neck movement - and they are often wheelchair-bound. Consequently, washing their hair can be quite painful, and hairdressing takes more time due to transfer and installation times. One direct result is that on average three fewer clients can be seen in a day. The engineer came to the innovation jury with videos taken by his wife, movies of the prototypes he built in his garage (see Figure 2) and testimonies of elderly clients in conventional and novel hairdressing chairs. As he was convincing (proofs of usefulness and proofs of concept), he patented his inventions (proof of newness) and the market was apparently huge (proof of profitability), he was not only selected by Silver Valley but also incubated for one year. He created a company called Esthetic Handi Access (http://www.esthetic-handi-access.com/fr/) that started industrial production with a full order book, because he was now able to prove that hairdressers of the elderly have the same number of clients per day than any other hairdresser (proof of profitability). 
Yannau B., Farel R., Cluzel F., Bekhradi A., Zimmer B. (20I6) 'The UNPC innavativeness set of indicatars far idea ar praject selection and maturation in healthcare', 5, №. 3-4, pp. 205-2Z1, Internationa/ Lourna/ of Design Lreativity and Innavation, dai: 10.1080/21650349.2016.1161562

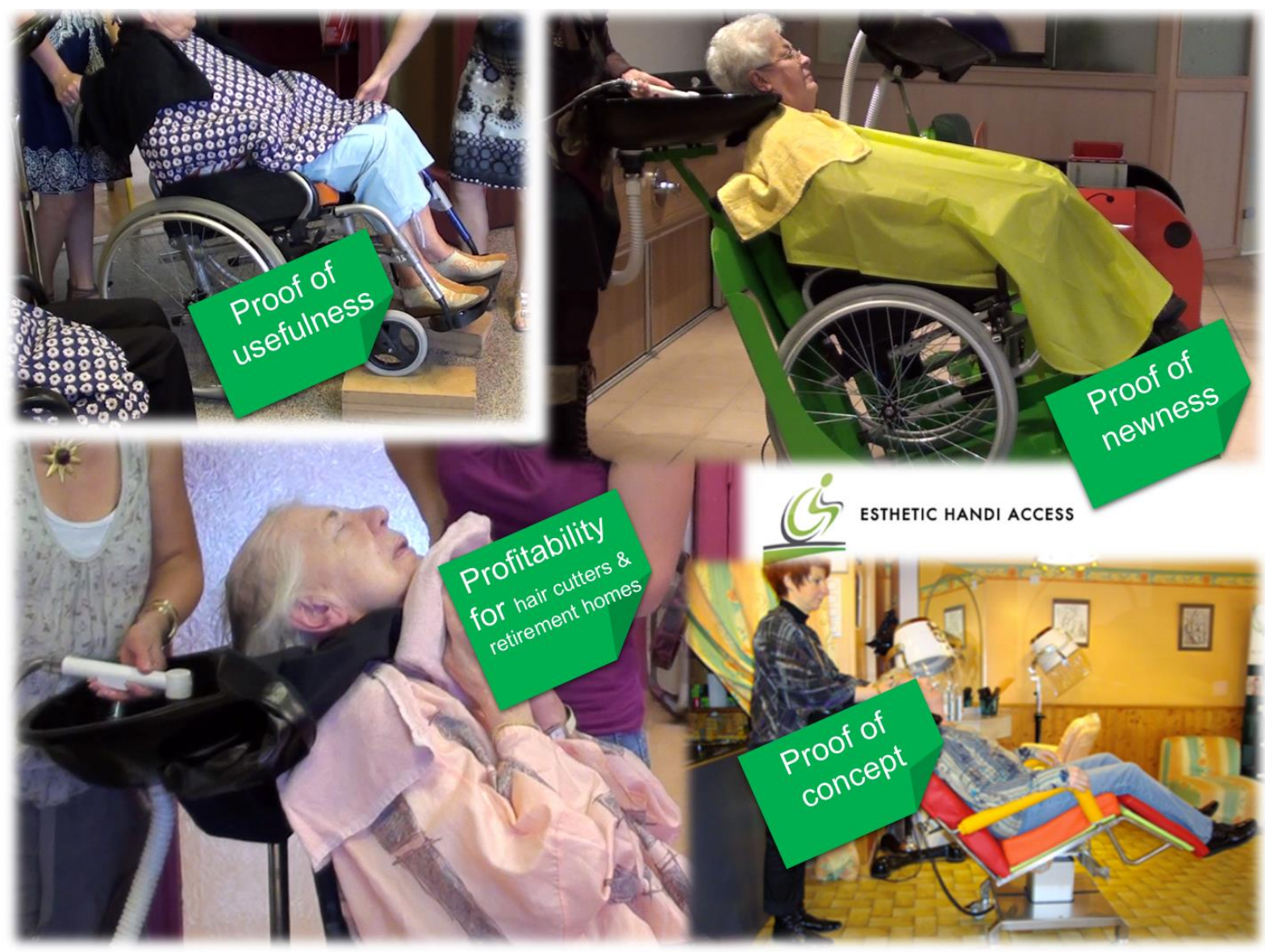

Figure 2. UNPC proofs for the hairdressing chair and furniture for elderly

\subsection{Elimination of deficient innovative projects thanks to UNPC}

The third example in Figure 3 shows an innovative walking frame, sketched in diverse configurations by splendid pictures. This walking frame is made of two engine-assisted triangle caterpillars designed to supposedly climb sidewalks and obstacles while maintaining stability and verticality. This was apparently a first-rate idea, since the young industrial designer, author of this proposal, had just received the first substantial prize of a famous innovation competition. Here, usefulness is not questionable but the attention of some jury members focused on the effectiveness of the system in a typical usage situation. One question posed to the industrial designer was: "What happens if the aided person grasping the two handles suddenly stumbles?". The designer was unable to answer and was even troubled. According to her explanations, the walking frame should have sped up as the user pushed the handles forward on stumbling, resulting in a dangerous fall. This is a typical example of a positive amplification open loop in control theory, a discipline which was unfamiliar to the industrial designer. In addition, the vertical stabilization and stiffness of the walking frame should enable a sophisticated level of control, and this element was ignored by the innovator. In conclusion, there was evidence of a lack of proof of concept. The project was not selected by Silver Valley and the entrepreneur abandoned the project two years later. 


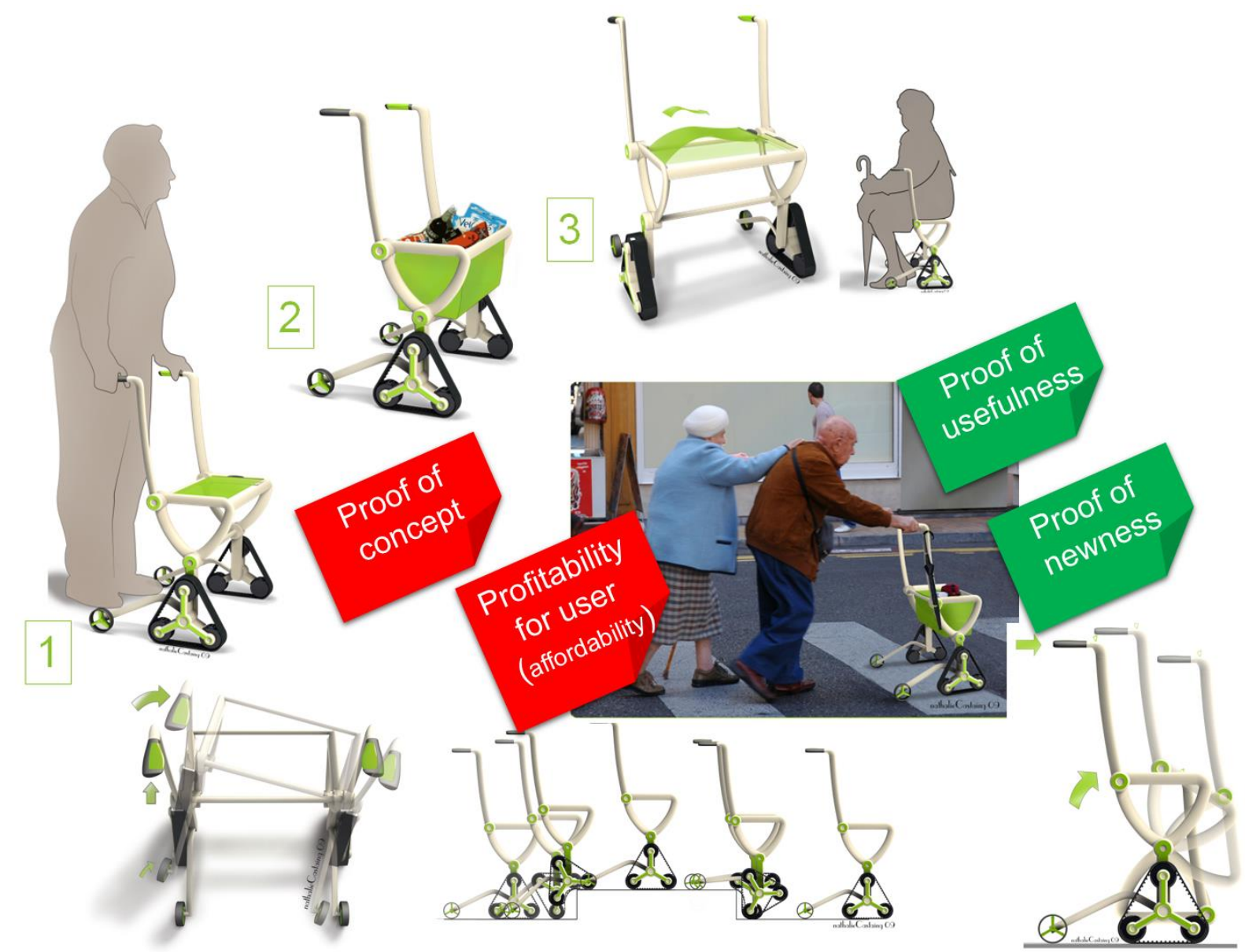

Figure 3. UNPC proofs for the walking frame project

Another group of six highly-educated engineers and business managers from prestigious universities proposed a concept of developing First-Person-Shooting (FPS) applications to (a) detect (b) prevent by training (c) reeducate once started, people suffering from Alzheimer's disease. In FPS games, the gamers must, within a limited time, target some graphical objective and press the button - for example, to shoot or pop a balloon. They based their proposal on a unique and dated scientific publication - not provided to jury members - that a correlation - no figures provided - had been established between Alzheimer's disease and the ability to get a high score at FPS contests (see Figure 4). This group of six was respectable since they had founded a startup companies 2 years before and launched two e-healthcare apps. But there was not enough evidence that useful information could be derived from personal prowess in this type of game, particularly for people not familiar with gaming (lack of proof of concept). In addition, they wanted to develop a pre-diagnosis platform for automatically making appointments with neurologists, as soon as the first signs of Alzheimer's disease were detected: patient states degrade in the long wait for appointments with neurologists, who are overbooked. Again, the jury considered such assertions to be based on false explanatory principles and misguided interpretation, and more research would have been necessary before starting product-service development. The service effectiveness was far from being proven (lack of proof of usefulness). In addition, the benefits for both patients and health professionals were probably inexistent (lack of proof of profitability). Finally, this project was not selected, and the startup gave up this project later. 
Yannou B., Farel R., Cluzel F., Bekhradi A., Zimmer B. (20I6) 'The UNPC innovativeness set of indicators for idea oг project selection and maturation in healthcare', 5, №. 3-4, pp. 205-221, Internationa/ Jaurna/ af Design Creativity and Innavation, dai: 㐰.1080/21650349.2016.1161562

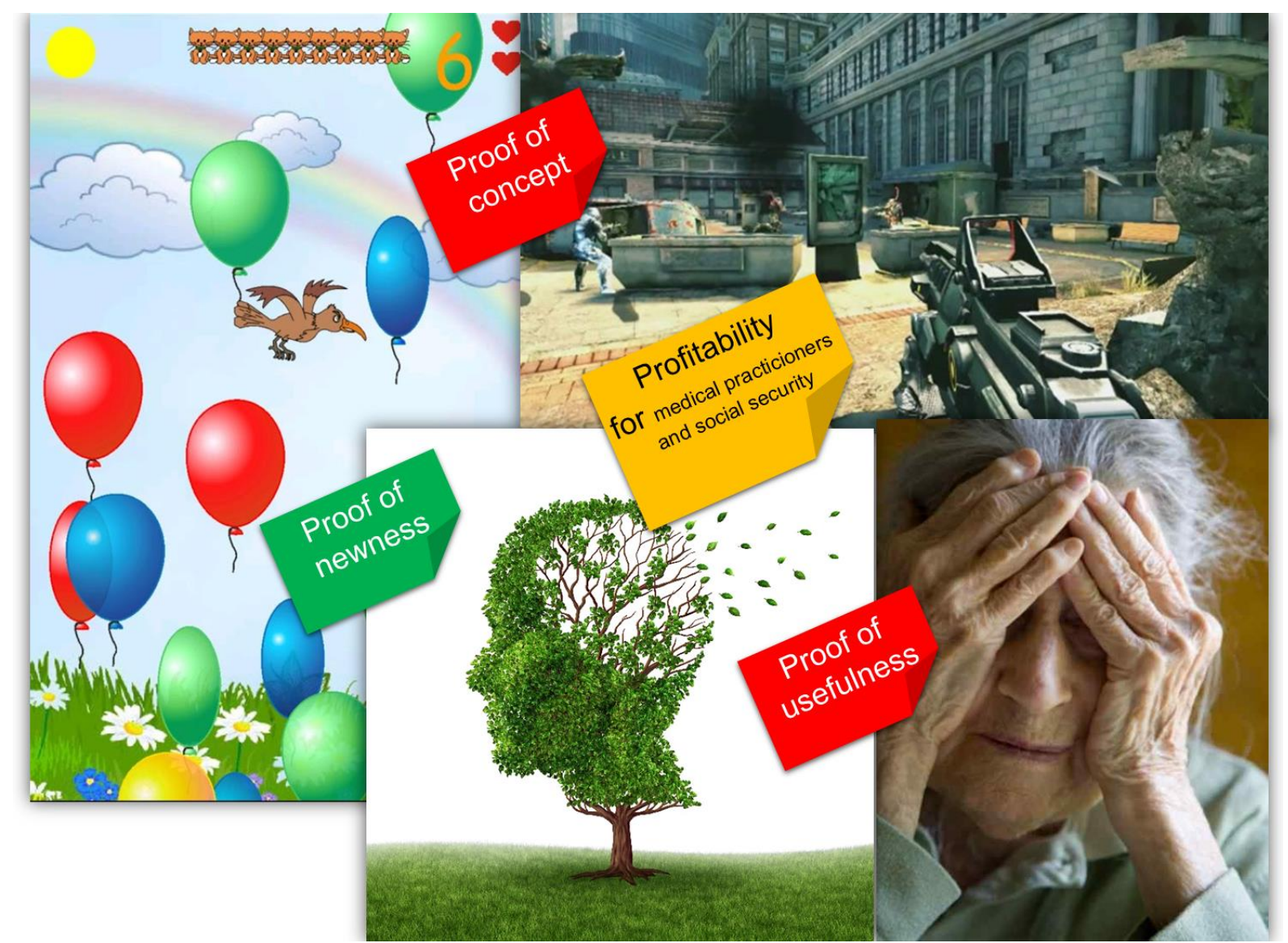

Figure 4. UNPC proofs for the Alzheimer-First-Person-Shooting project

\section{Proposal of the UNPC monitoring process for idea maturation}

As our UNPC innovativeness model proved to be relevant in the context of "design for healthcare", we now propose using it as a framework for monitoring an innovative idea or project and increasing its maturity and likelihood of being successful on the market.

The UNPC monitoring process for idea maturation we propose is as follows (see Figure 5):

1. Start from a value bucket, generate a set of ideas, and describe each of them succinctly. For each idea:

2. Proceed to a SWOT analysis (Strengths, Weaknesses, Opportunities, and Threats). Under Strengths and Opportunities, list arguments in favor of UNPC proofs. Under Weaknesses and Threats, list arguments not in favour of UNPC proofs.

For each argument:

3. The design team members assess both impact and certainty of each argument. An argument of $\mathrm{S}$ or $\mathrm{O}$ type has a positive impact (between 0 and 3, see Table 2). An argument of $\mathrm{W}$ or $\mathrm{T}$ type has a negative impact (between -3 and 0 ). The impact is the importance or magnitude of the argument for making the proof robust.

4. For each idea, an idea UNPC impact vector is automatically calculated as the average of argument impacts under each $\mathrm{U}, \mathrm{N}, \mathrm{P}$ or $\mathrm{C}$ proof.

5. For each idea, an idea UNPC certainty vector is updated by the design team, each new argument brought in $\mathrm{U}, \mathrm{N}, \mathrm{P}$ or $\mathrm{C}$ category is assumed to maintain or increase the certainty.

6. Creativity is continued to find $\mathrm{U}, \mathrm{N}, \mathrm{P}$ or $\mathrm{C}$ positive or negative arguments and, for each new argument, the process loops back to step 4 until 
a. Certainty is high for one of the $\mathrm{U}, \mathrm{N}, \mathrm{P}$ or $\mathrm{C}$ proofs and the corresponding impact is lower than an admissible threshold, so the idea is abandoned.

b. The certainty is high for all $\mathrm{U}, \mathrm{N}, \mathrm{P}$ and $\mathrm{C}$ proofs with impacts greater than minimal thresholds, so the idea is selected.

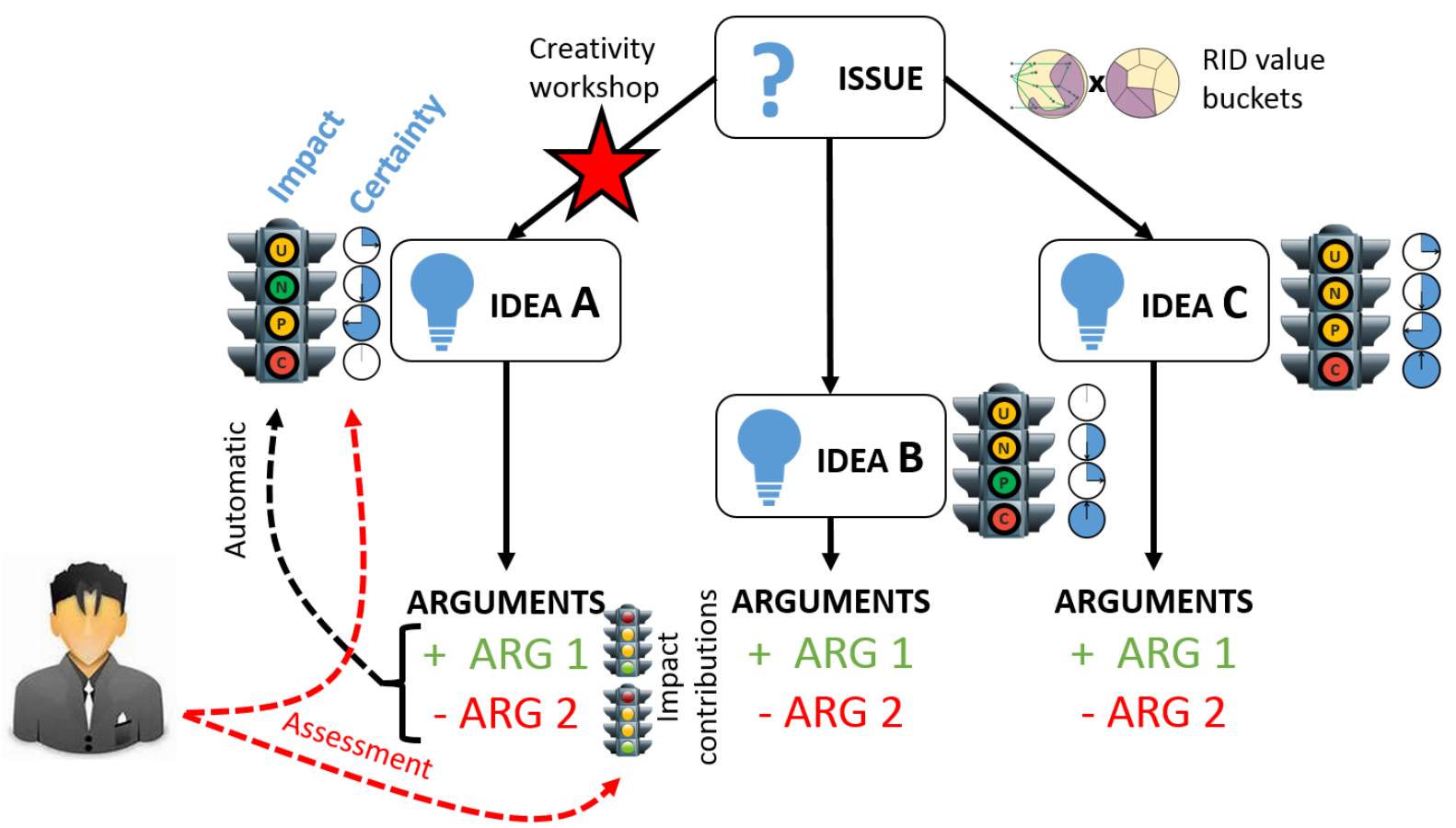

Figure 5. Principles of the UNPC monitoring process: gathering UNPC evidence, automatic calculation of idea impact, manual updating of idea certainty

\section{Applying UNPC monitoring to an e-healthcare application}

\subsection{Initiating the UNPC monitoring process}

The UNPC-monitor method and tool are presented along with a true innovation project performed for a company called Withings. This led to a prototype (see Figure 6) and then to upgrade a commercial product (see Figure 10). Following an RID process, the design team starts with the following initial idea "Withings company develop devices and smartphone applications that can monitor health parameters like weight, heart rate, physical activity and sleep. Let us explore a new usage context". During the problem-setting stage, an observation is made: "The increased presence of social networks in relations between people tends to reinforce motivation to exercise". A value bucket is finally expressed as follows: "To increase motivation of individuals having different age, gender and occupation to exercise regularly through networking emulation." The issue expressed for starting creativity is slightly modified into: "How to make an exercise application more motivational through social networks". 
Yannau B., Farel R., Cluzel F., Bekhradi A., Zimmer B. (20I6) 'The UNPC innavativeness set of indicatars far idea ar praject selection and maturation in healthcare', 5., №. 3-4, p.. 205-221, Internationa/ Jaurna/ of Design Lreativity and Innovation, dai: 10.1080/21650349.2016.1161562
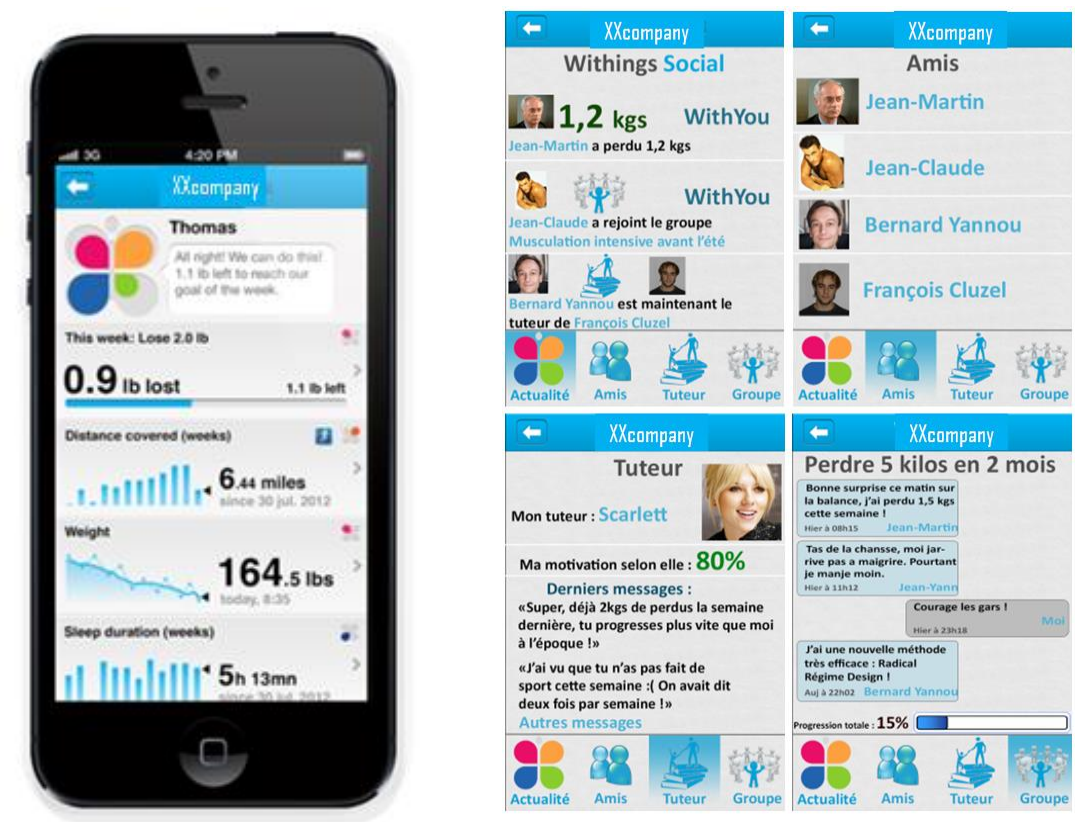

Figure 6. The prototype result of the innovation project of an e-healthcare application for Withings

The brainstorming session led to three ideas:

- Idea A: (Video gaming) This idea is inspired from video-games. The user gains levels according to the degree of completion of their fitness goals. The user is awarded points and trophies as he/she advances. These points can be redeemed against gifts.

- Idea B: (Community concept) This idea involves social networking. The user shares his/her profile and progress with a vast network of people who are their friends or other users of Withings applications. Such an exchange between users in a group can be a source of motivation. It gives the user a personalized space in which they can interact with like-minded people and the people who matter to them.

- Idea C: (Fun and community concept) This idea is an amalgamation of the first two ideas and includes both gamification and community. The users are divided into appropriate teams and they can compete among themselves. The competitive spirit can be a great motivator.

\subsection{Concurrent monitoring of ideas and final selection}

The SWOT analysis for idea A led to 12 arguments ( 4 for U, 4 for N, 3 for P, 1 for C) given in Figure 7. Nine of them are positive in terms of impact and three of them negative, leading to an idea impact vector of $(\mathrm{U}=0.5, \mathrm{~N}=0.58, \mathrm{P}=0.33, \mathrm{C}=1.00)$. Certainty is $100 \%$ for $\mathrm{U}$ and $\mathrm{C}$, meaning that we are sure that proof of usefulness is average and proof of concept is high. For newness and profitability there are serious elements or presumptions (certainty is 50\%) that newness is average and profitability weak. But there is still hope that, looking for more arguments, one could improve the certainty for better impacts. Brainstorming must then be pursued. A graphical interface was developed to manage the idea rating (see Figure 7 for idea A). Similar arguments are found and assessed for idea B (Figure 8) and idea C (Figure 9). 


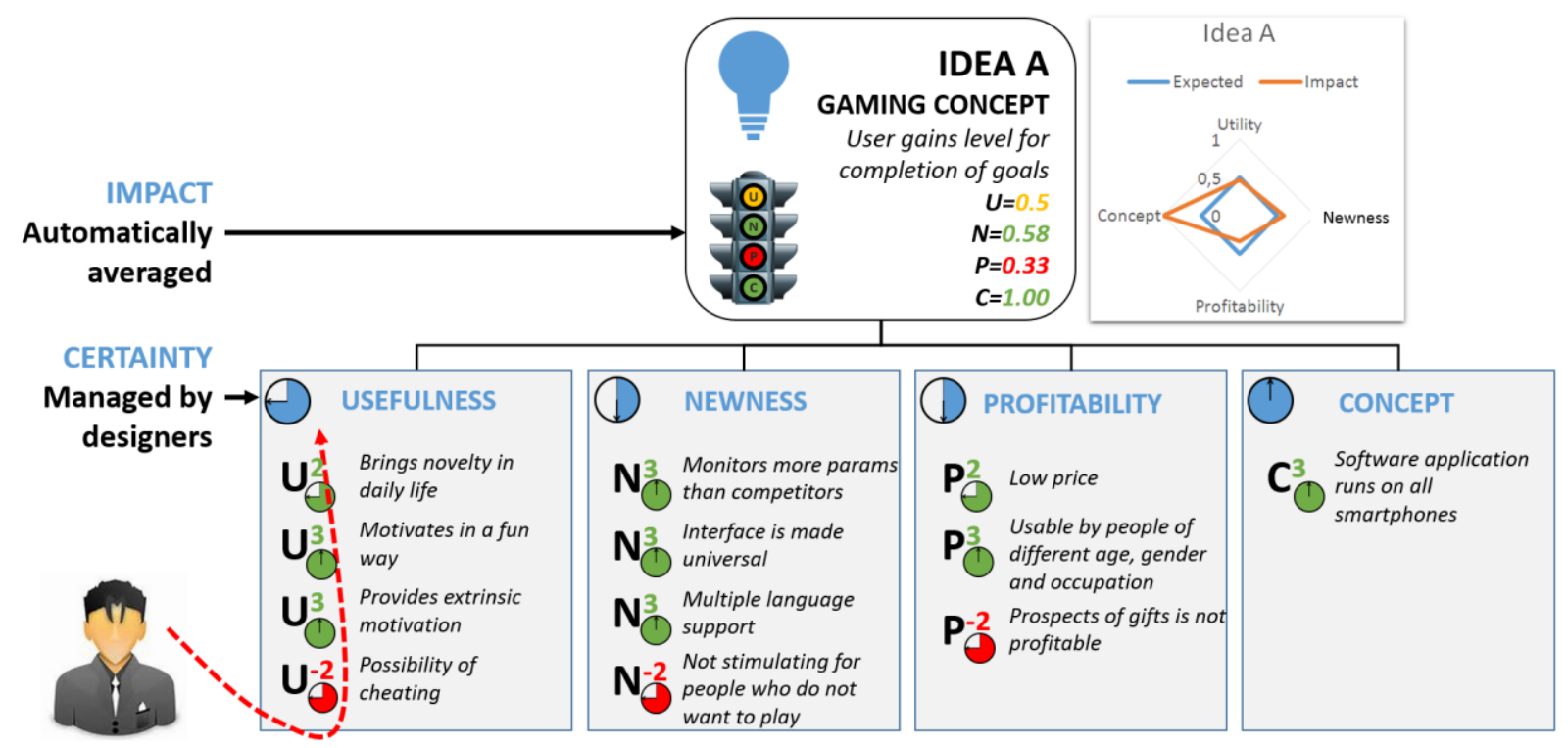

Figure 7. UNPC arguments, impact and certainty vectors for idea A, represented in UNPC-monitor tool

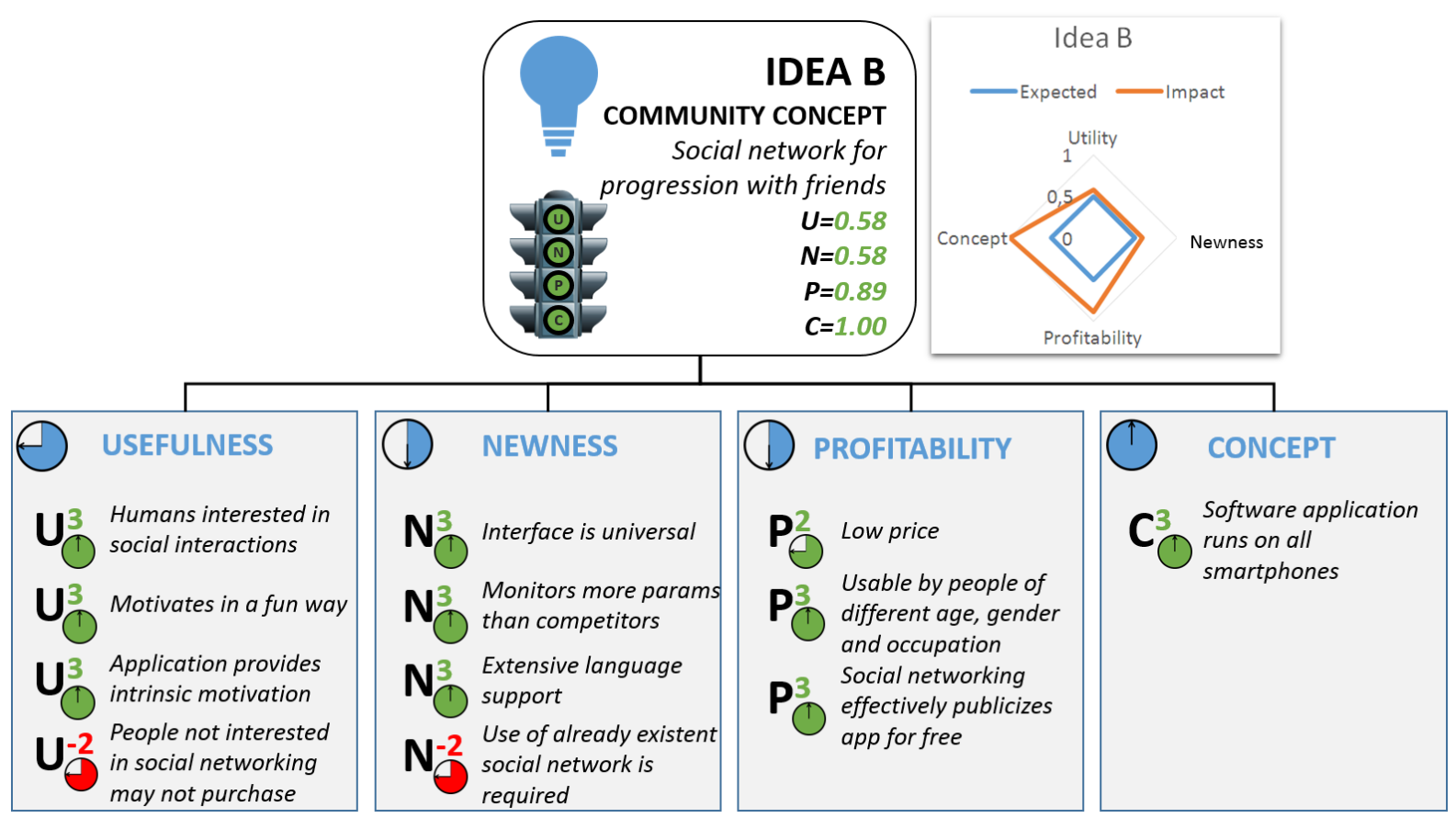

Figure 8. UNPC arguments, impact and certainty vectors for idea B, represented in UNPC-monitor tool

After the primary SWOT analyses on the ideas, the process becomes dynamic. A general graphical dashboard (see Figures 11 and 12) allows to opportunistically justify the search for a new argument of $\mathrm{U}, \mathrm{N}, \mathrm{P}$ or $\mathrm{C}$ type for a given idea. The ideation process may be traced because the reasons for brainstorming around a given question is motivated by insufficient certainty, i.e. poor idea maturation. In addition, abandoning an idea or preference of one idea over another may now be easily justified and guided. 
Yannau B., Farel R., Cluzel F., Bekhradi A., Zimmer B. (20I6) 'The UNPC innavativeness set of indicatars far idea ar praject selection and maturation in healthcare', 5., №. 3-4, p.. 205-221, Internationa/ Jaurna/ of Design Lreativity and Innovation, dai: 10.1080/21650349.2016.|161562

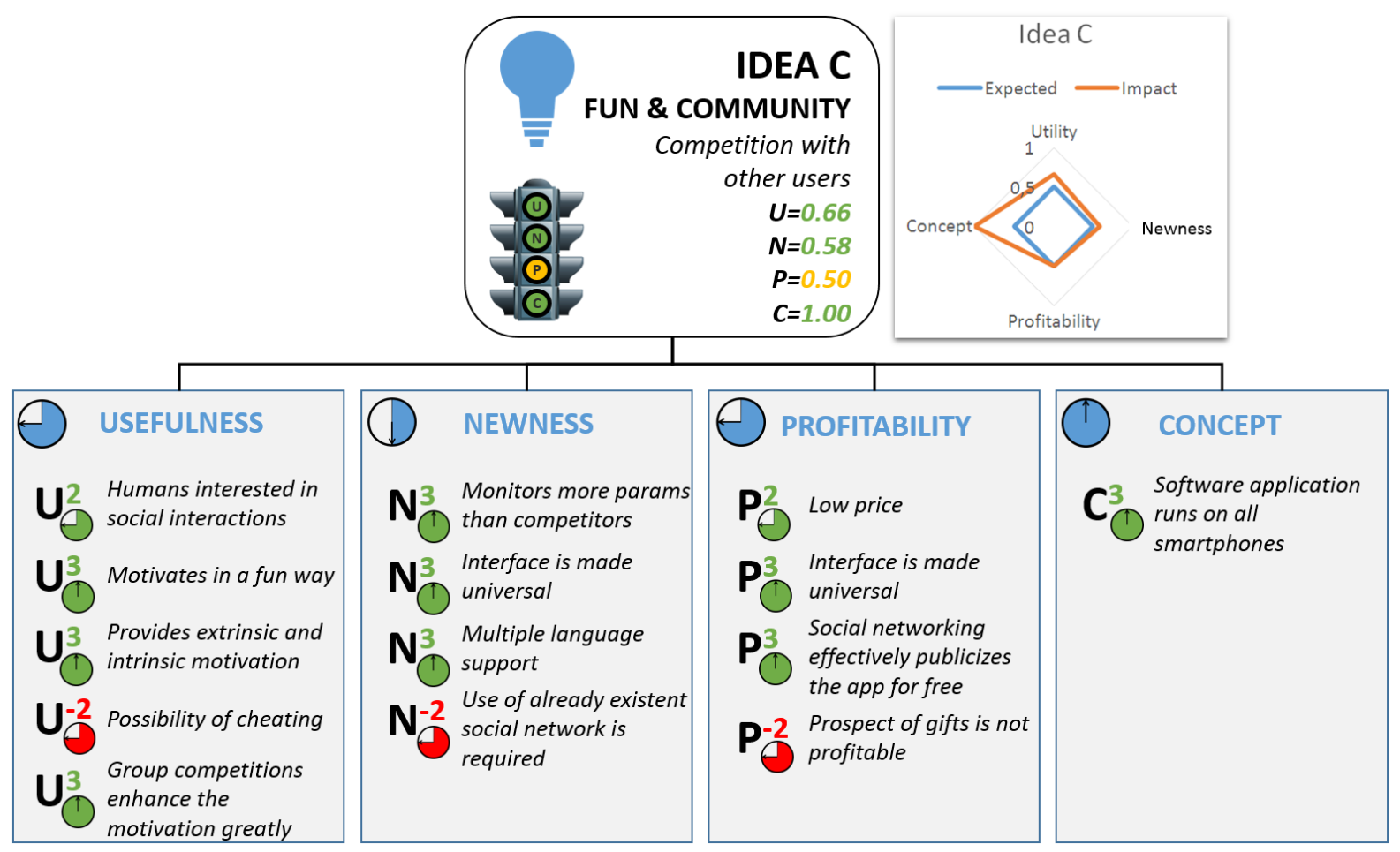

Figure 9. UNPC arguments, impact and certainty vectors for idea C, represented in UNPC-monitor tool

\section{Results and discussion}

The UNPC monitoring process applied to an initial immature idea in the context of Withings activity tracking and e-healthcare business has been successful. Indeed, it led to augment an already popular smart application named Health Mate (see Figure 10). A personal health coaching facility was added.
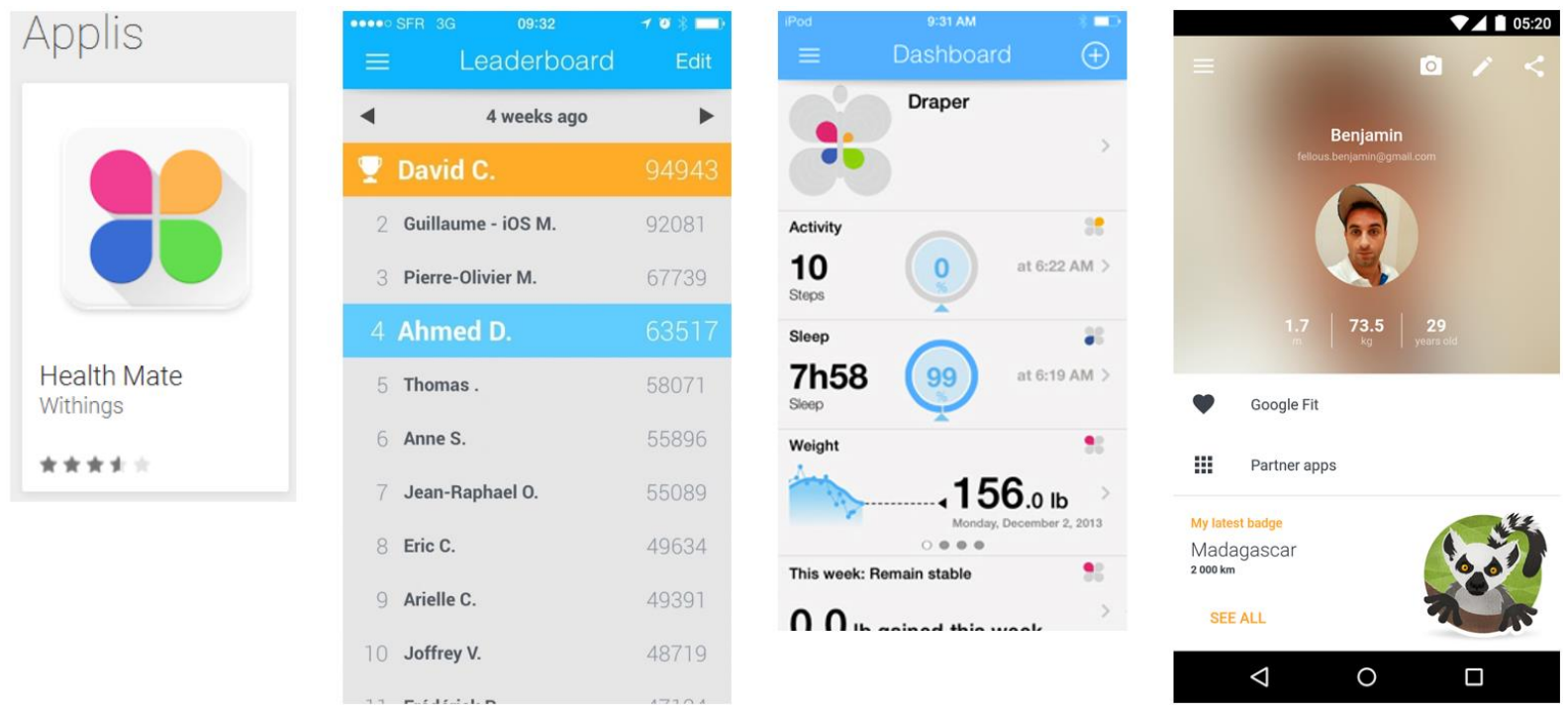

Figure 10. How Withings Health Mate application has been impacted by our innovative project 
The authors developed a design software called "UNPC-monitor tool". This design tool displays two complementary dashboards, an Excel one (see Figure 11) and a graphical one (see Figure 12). This tool helps designers see which aspect of innovativeness is weak and to target the component ( $\mathrm{U}, \mathrm{N}, \mathrm{P}$ or $\mathrm{C})$ that is deficient, thus collecting more relevant and targeted information.

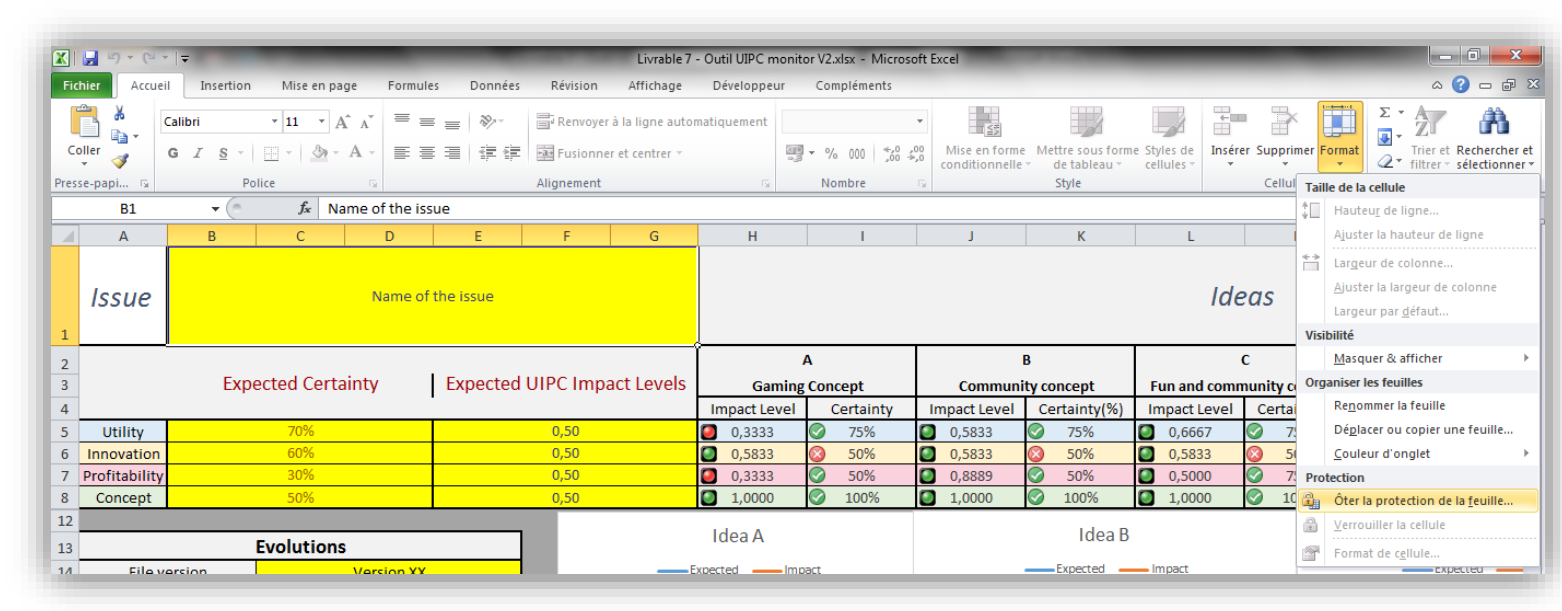

Figure 11. The general Excel dashboard of UNPC-monitor tool for ideas A, B and C

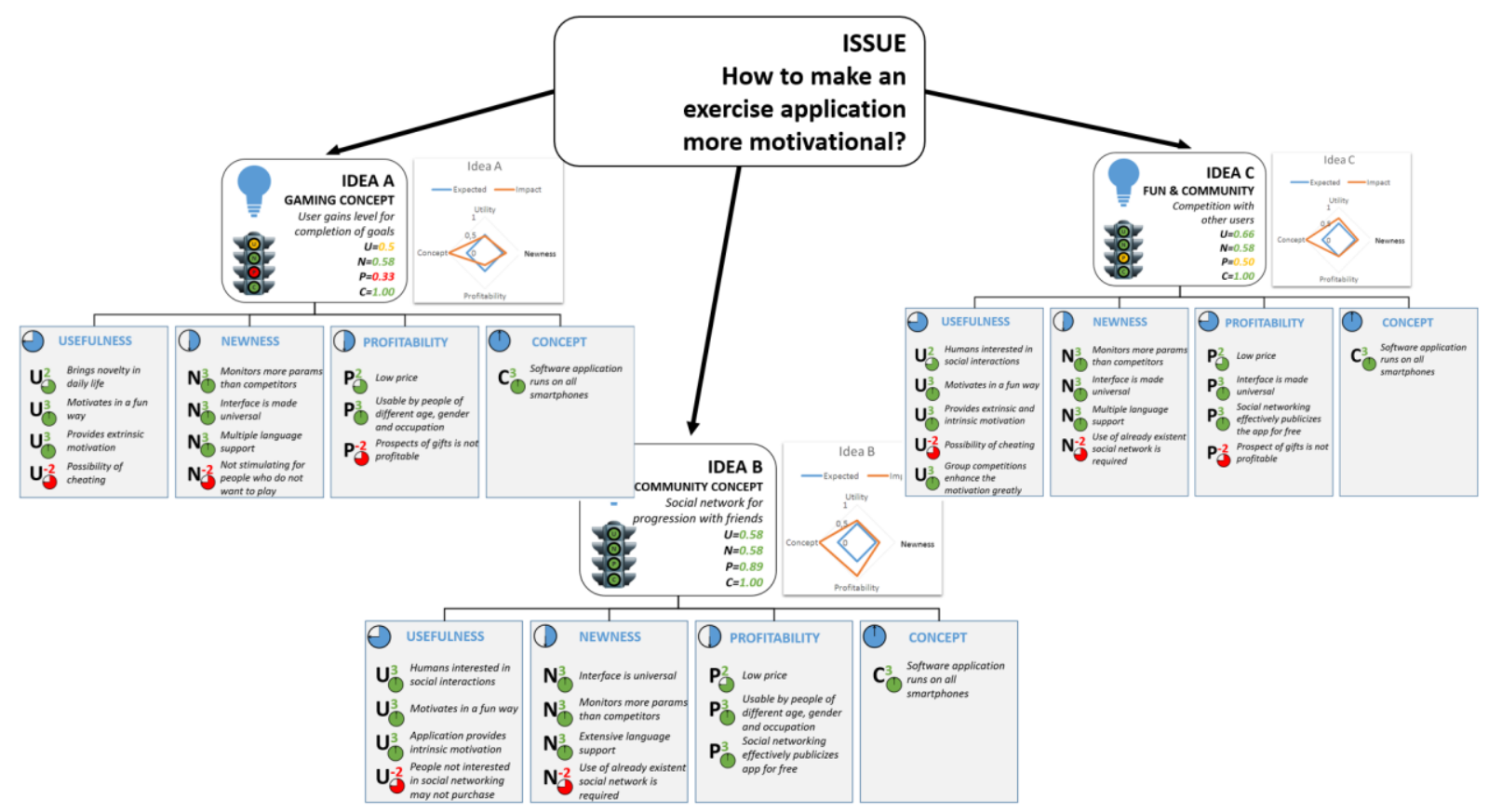

Figure 12. The general graphical dashboard of UNPC-monitor tool for ideas A, B and C

In practice, the authors use the UNPC-monitor tool within the two-stage ideation process of Radical Innovation Design (Yannou, 2015). This ideation process sketched in Figure 13 is made of $(n+1)$ brainstorming sessions ( $n$ being the number of value buckets) along a scenario creativity stage to come up with one - or several - dreamt usage scenario, and a concept creativity stage where this scenario is embodied in a conceptual product-service solution. 


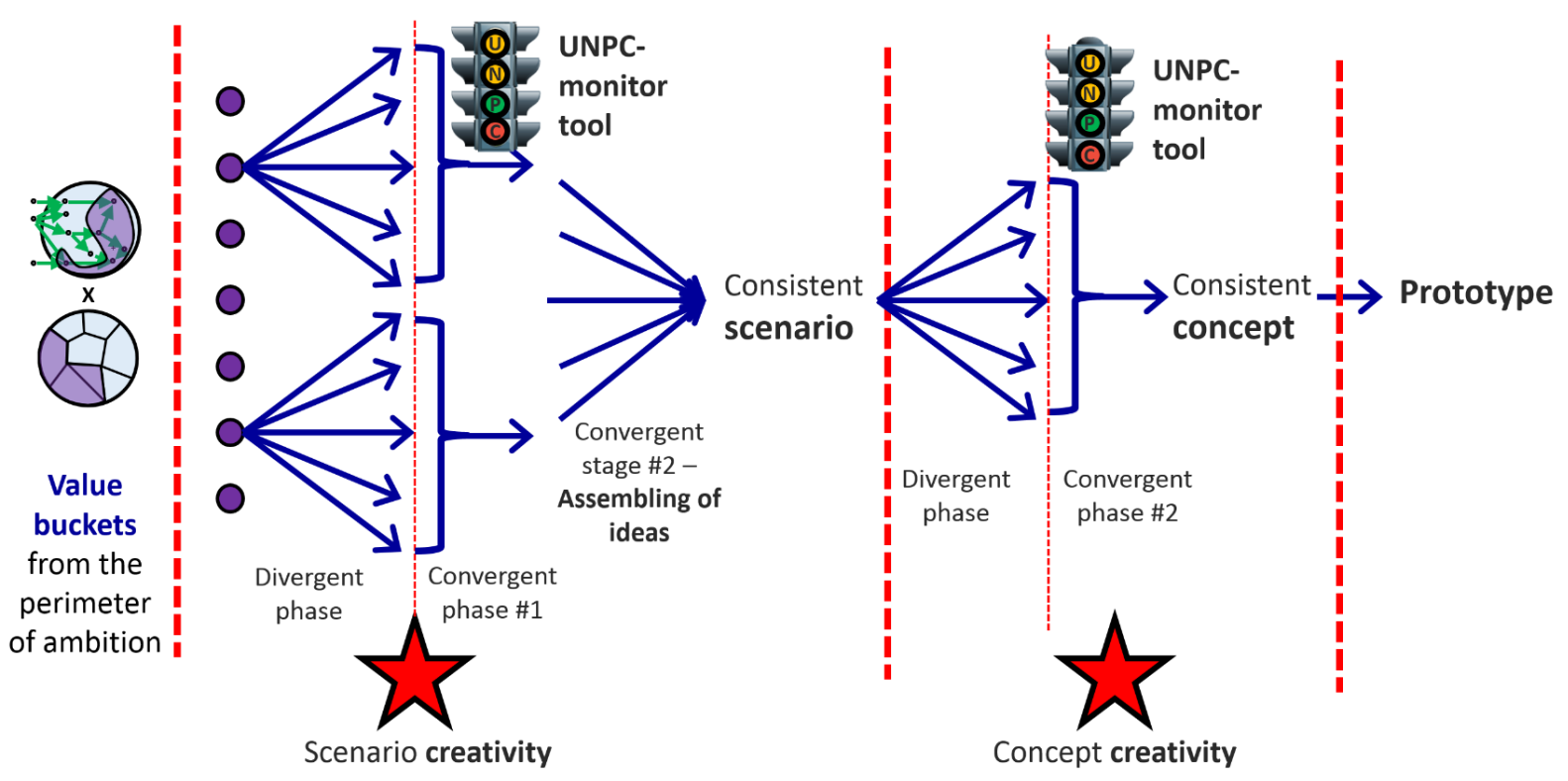

Figure 13. The two-stage RID ideation process where UNPC monitoring process may be applied

In summary, measuring and controlling ideation is different from monitoring innovativeness. We noted that an idea in an innovation process was rarely assessed for its value-add or usefulness, its profitability and its feasibility or proof of concept. We adopt here the UNPC model for assessing the likelihood of an idea becoming a successful innovation as already shown in (Yannou, Zimmer, et al., 2013) in situations of business innovation competitions organized by private/public initiatives as well as within companies for selecting promising innovation seeds.

We propose a process to concurrently assess the UNPC impact and certainty vectors of a set of ideas. The process is initiated by idea SWOT analyses and it becomes dynamic, looking opportunistically for new evidence or arguments for augmenting the certainty of UNPC proofs of the ideas. The process ends when sufficient certainty is reached, and the best idea with the best UNPC impact is then chosen. Of course, trade-offs must often be made between usefulness, newness, profitability and concept advantages. What these trade-offs will be depends on the project, the product line and company strategy.

The authors have tested and developed this model over a period of four years in real entrepreneurial conditions; it is a practical application of research in design. This is the first time we have illustrated the use of the UNPC model for innovative project selection (section 3). Four examples illustrate how the jury members changed their decision to select - or not - a given project after considering the whole set of UNPC proofs. These examples demonstrate how UNPC is used qualitatively by jury members.

We do not think that UNPC is an elaborate model. On the contrary, the model, as defined by the definitions of Table 1, is a basic but relevant compass to make decisions for selecting worthy innovative ideas/projects in the healthcare sector. In the Silver Valley context, there is now a published book of cases which is distributed to applicants.

In addition, the proposed UNPC-monitor tool has proved to be useful in the case of activity tracking and personal health coaching with the upgrading of a popular smart application. Proving the efficiency of our UNPC monitoring in other cases, i.e. the convergence of incubated ideas, will form the next step of our research.

\section{Acknowledgement}

We would like to thank Anand Parikh for his work on developing the UNPC-monitor software platform. 


\section{References}

Bekhradi, A., Yannou, B., Farel, R., Jena, S., \& Zimmer, B. (2014, May 19 - 22). Simulating global utility of design solutions to elderly falls by building relevant usage segmentation. Paper presented at the International Design Conference, Dubrovnik, Croatia.

Bekhradi, A., Yannou, B., Farel, R., Zimmer, B., \& Chandra, J. (2015). Usefulness Simulation of Design Concepts. Journal of Mechanical Design, 137(7). doi:10.1115/1.4030180

Boatwright, P., \& Cagan, J. (2010). Built to Love: Creating Products That Captive Customers, the Science of Product Emotion. San Francisco: Berrett-Koehler Publishers, Inc.

Chakrabarti, A., Sarkar, P., Leelavathamma, B., \& Nataraju, B. S. (2005). A Functional Representation for Aiding Biomimetic and Artificial Inspiration of New Ideas. AI EDAM, 19(2), 113-132.

Christensen, C. (2003). The Innovator's Solution: Creating and Sustaining Successful Growth: Harvard Business School Press.

Christensen, C. (2011). The Innovator's Dilemma: The Revolutionary Book That Will Change the Way You Do Business: HarperBusiness.

Goldschmidt, G. (1990). Linkography: assessing design productivity. Paper presented at the Tenth European Meeting on Cybernetics and Systems Research, Singapore.

Goldschmidt, G., \& Tatsa, D. (2005). How good are good ideas? Correlates of design creativity. Design Studies, 26(6), 593-611.

Grace, K., Maher, M. L., Fisher, D., \& Brady, K. (2014, 23-25 June). Modeling Expectation for Evaluating Surprise in Design Creativity. Paper presented at the DCC'14: International Conference on Design Computing and Cognition, London, UK.

Kan, J., \& Gero, J. (2008). Acquiring information from linkography in protocol studies of designing. Design Studies, 29(4), 315-337.

Kazakci, A. O., Gillier, T., Piat, G., \& Hatchuel, A. (2014, 23-25 June). Brainstorming vs. Creative Design Reasoning: A Theory-Driven Experimental Investigation Of Novelty, Feasibility And Value Of Ideas. Paper presented at the DCC'14: International Conference on Design Computing and Cognition, London, UK.

Kim, C. W., \& Mauborgne, R. (2005). Blue ocean strategy - How to create uncontested market space and make the competition irrelevant. Boston, USA/MA: Harvard Business School press.

Kornish, L. J., \& Ulrich, K. T. (2014). The Importance of the Raw Idea in Innovation: Testing the Sow's Ear Hypothesis. Journal of Marketing Research, 51(1), 14-26.

Maher, M., \& Fisher, D. (2012). Using AI to evaluate creative designs. Paper presented at the 2nd International Conference on Design Creativity.

Sarkar, P., \& Chakrabarti, A. (2011). Assessing design creativity. Design Studies, 32(4), 348-383. Retrieved from http://www.sciencedirect.com/science/article/pii/S0142694X11000111

Shah, J. J., Smith, S. M., \& Vargas-Hernandez, N. (2003). Metrics for measuring ideation effectiveness. Design Studies, 24(2), 111-134.

Talke, K., Salomo, S., Wieringa, J. E., \& Lutz, A. (2009). What About Design Newness? Investigating the Relevance of a Neglected Dimension of Product Innovativeness. Journal of Product Innovation Management, 26(6), 601-615.

Thompson, S. C., \& Paredis, C. (2010, August 15-18). An Introduction to Rational Design Theory. Paper presented at the IDETC/DTM: ASME International Design Engineering Technical Conferences \& Computers and Information in Engineering Conferences / Design Theory and Methodology Conference, Montreal, Canada.

Wright, P. (2012). The three levels of innovation. CEO Forum(http://www.ceoforum.com.au/articledetail.cfm?cid=6143\&t=/Paul-Wright-Invetech/The-three-levels-of-innovation). $\quad$ Retrieved $\quad$ from http://www.ceoforum.com.au/article-detail.cfm?cid=6143\&t=/Paul-Wright-Invetech/The-three-levelsof-innovation

Yannou, B. (2015, July 27-31). Supporting need seeker innovation: The Radical Innovation Design methodology. Paper presented at the ICED: International Conference on Engineering Design, Milano, Italy.

Yannou, B., Farel, R., \& Cluzel, F. (2015, Jan 12-14). The UIPC monitor tool for augmenting idea maturity with proofs of utility innovation profitability and concept. Paper presented at the ICDC: The Third International Conference on Design Creativity, Bangalore, India.

Yannou, B., Jankovic, M., Leroy, Y., \& Okudan Kremer, G. E. (2013). Observations from radical innovation projects considering the company context. Journal of Mechanical Design, 135(2). doi:10.1115/1.4023150

Yannou, B., Yvars, P.-A., Hoyle, C., \& Chen, W. (2013). Set-based design by simulation of usage scenario coverage. Journal of Engineering Design, 24(8), 575-603. doi:10.1080/09544828.2013.780201 
Yannou B., Farel R., Cluzel F., Bekhradi A., Zimmer B. (20I6) 'The UNPC innovativeness set of indicators for idea oг project selection and maturation in healthcare', 5, №. 3-4, pp. 205-221, Internationa/ Jaurna/ of Design Creativity and Innavatian, dai: 10.1080/21650349.2016.1161562

Yannou, B., Zimmer, B., Farel, R., Jankovic, M., \& Stal Le Cardinal, J. (2013). Proofs of Utility, Innovation, Profitability and Concept for innovation selection. Paper presented at the ICED: 19th International Conference on Engineering Design, Seoul, Korea. 